\title{
A CONTRIBUIÇÃO DA INTERSETORIALIDADE NA PROMOÇÃO DA SEGURANÇA ALIMENTAR E NUTRICIONAL E NO FOMENTO À AGROINDÚSTRIA FAMILIAR NO NORTE DE MINAS GERAIS ${ }^{1}$
}

\author{
Leandro Patrício Pereira Lima ${ }^{2}$ \\ Katia Cilene Tabai ${ }^{3}$
}

\begin{abstract}
RESUMO:
O presente artigo tem como objetivo traçar uma análise da percepção de atores sociais chave na execução e envolvimento com políticas públicas de segurança alimentar e nutricional e no fomento a agroindústria familiar, apresentando a intersetorialidade como processo de efetivação das ações. Na oportunidade foi analisado com os atores chave a efetivação destas políticas no ambiente da agroindústria no município de Bonito de Minas-MG. Buscou-se verificar o entendimento dos atores sociais das políticas públicas onde os programas e ações que tratam da Agricultura Familiar e Agroindústria atenderam, de forma direta ou indireta, a agroindústria de Água Doce. Na pesquisa foram revelados fatores que caracterizam as fragilidades do Estado em trabalhar as questões de intersetorialidade na temática, mas para o desenvolvimento da agroindústria oportunizou maior amadurecimento na gestão da produção e envolvimento organizacional em rede de cooperação e produção de frutos do cerrado na região norte do Estado.
\end{abstract}

Palavras-chave: Intersetorialidade, Agroindústria Familiar, Segurança Alimentar e Nutricional, Políticas Públicas.

\section{THE CONTRIBUTION OF INTERSECTORIALITY IN PROMOTING FOOD AND NUTRITIONAL SECURITY AND FAMILY AGROINDUSTRY IN THE NORTH OF MINAS GERAIS}

\begin{abstract}
:
The objective of this article is to outline an analysis of the perception of the key social actors in the implementation and involvement with public policies on food and nutritional security and in fostering the family agroindustry, having the intersectoriality as a process of realization of the actions. The opportunity was analyzed with the key actors the effectuation of these policies in the environment of agribusiness in the municipality of Bonito de Minas-MG. The opportunity was analyzed with the key actors the effectuation of these policies in the environment of agroindustry in the municipality of Bonito de Minas-MG. We sought to check the understanding of social actors of public policies where the programs and actions that deal with the family farming and agroindustry met, directly or indirectly, the agroindustry of Agua Doce. In the survey were revealed factors that characterize the weaknesses of the State in working the issues of intersectorality in the theme, but for the development of the agroindustry, it provided greater maturity in the management of production and organizational involvement in cooperation network and fruit production in the cerrado in the northern region of the State.
\end{abstract}

Keywords: Intersectorality, Family Agroindustry, Food and Nutrition Security, Public Policies.

\footnotetext{
${ }^{1}$ Este capítulo foi baseado parcialmente na dissertação de mestrado do primeiro autor, a saber, Leandro Patrício Pereira Lima, Extrativismo e segurança alimentar: a agroindustrialização de frutos do cerrado, 133 p. 2020. Dissertação (Programa de Pós-graduação em Agricultura Orgânica) - Universidade Federal Rural do Rio de Janeiro.

2 Mestre em Agricultura Orgânica pelo Programa de Pós-Graduação em Agricultura Orgânica - PPGPAO. Universidade Federal Rural de Rio de Janeiro - UFRRJ. Engenheiro Agrônomo. Analista de desenvolvimento econômico e social do IDENE (Instituto de Desenvolvimento do Norte e Nordeste de MG ). Grupo de Pesquisa do CNPq: Segurança Alimentar e Nutricional (SAN). Email: leandrolimaagro@yahoo.com.br

${ }^{3}$ Professora Titular. Universidade Federal Rural do Rio de Janeiro - UFRRJ. Orientadora do trabalho pelo Programa de Pós- Graduação em Agricultura Orgânica - PPGPAO. Líder do Grupo de Pesquisa do CNPq: Segurança Alimentar e Nutricional (SAN). Email: ktabai@ufrrj.br
} 


\section{INTRODUÇÃO}

O Estado de Minas Gerais, na busca do desenvolvimento sustentável com planejamento articulado, melhoria das condições de vida de todos os mineiros e a redução dos níveis de pobreza e de desigualdades sociais, constituiu canais e mecanismos que propiciaram uma maior participação da população nas tomadas de decisão das políticas públicas (MINAS GERAIS, 2016a).

O planejamento das ações de políticas públicas, pela administração em 2015, contou com o apoio dos Fóruns Regionais de Governo em 17 Territórios de Desenvolvimento do Estado, envolvendo mais de 25.000 pessoas. Nas discussões e levantamentos das demandas regionais, foram apontadas, debatidas e priorizadas as ações de governo que poderiam constituir com efetividade as políticas de Estado, formatando assim Plano Mineiro de Desenvolvimento Integrado (PMDI) do período de 2016-2027 (MINAS GERAIS, 2016a, 2016b).

O PMDI é um instrumento constitucional com o objetivo de traçar um planejamento de longo prazo para o Estado de forma a reduzir as desigualdades regionais com a premissa do desenvolvimento econômico e social sustentável (MINAS GERAIS, 2016a).

As diretrizes foram vinculadas a todos os programas que compõem Plano Plurianual de Ação Governamental - PPAG, que é o instrumento de planejamento de médio prazo capaz de organizar e viabilizar a ação pública. É no PPAG que estavam as definições do escopo de atuação do Estado para o período de quatro anos (2016-2019), em um conjunto de 217 programas e 991 ações, que permitiram atender aos objetivos de longo prazo propostos pelo PMDI (MINAS GERAIS, 2016c, 2016d).

O monitoramento dos deputados estaduais, assegura o controle da efetividade das ações em comissões temáticas na Assembleia Legislativa de Minas Gerais, como a Comissão de Agropecuária e Agroindústria que trata o fomento da produção agropecuária, agroindustrialização e o desenvolvimento do negócio agrícola, a promoção do desenvolvimento rural e do bem-estar social no campo, entre outros e a Comissão de Direitos Humanos, que trata de segurança alimentar e nutricional e outros (ALMG, 2018).

As políticas públicas direcionadas para agricultura familiar são fundamentais na redução das desigualdades sociais, no desenvolvimento rural sustentável e no crescimento da região norte de Minas Gerais. A região está sob a influência do semiárido que promove secas prolongadas e perdas na produção agropecuária sendo o acesso aos frutos do cerado uma alternativa. Dada outra perspectiva, as agroindústrias familiares que atua localmente ou em microrregião auxiliam na SAN dos municípios, fornecendo alimentos com qualidade e de forma sustentável mesmo que as 
políticas públicas e ações locais de apoio à agregação de valor deixem a desejar quando se trata de fortalecer estrategicamente as iniciativas (GAZOLLA, 2014).

A intersetorialidade nas políticas públicas possibilita que setores dialoguem, participem dos processos, aproxima o público alvo e atua com inovação para reorganização da gestão, viabilizando uma nova relação entre os munícipes e os gestores (NEVES, 2017).

A intervenção do Estado com políticas públicas em SAN, valoriza e incentiva a população na adoção do consumo de alimentos regionais como fonte de vida e saúde e gera benefícios intersetoriais na região semiárida em relação a saúde, qualidade de vida e geração de emprego e renda (SAMPAIO, 2017).

O objetivo deste estudo foi traçar uma análise da percepção dos atores sociais na execução e envolvimento com políticas públicas de segurança alimentar e nutricional e no fomento a agroindústria familiar, apresentando a intersetorialidade como processo de efetivação das ações previstas no Plano Plurianual de Ação Governamental - PPAG 2016 - 2019 do estado de Minas Gerais. Na oportunidade, foram analisados com os atores a efetivação destas políticas no ambiente da agroindústria.

\section{Segurança Alimentar e Nutricional}

Neste estudo a Segurança Alimentar e Nutricional (SAN) é tratada conforme Burity et al. (2010), que classifica a insegurança alimentar como relativa (comprometimento da qualidade nutricional) e insegurança alimentar absoluta (não há disponibilidade em quantidade e qualidade por tempos determinados e que podem levar ao estado de fome e desnutrição). No campo das políticas públicas para a dimensão da $\mathrm{SAN}$, as ações devem contemplar não apenas a cadeia de produção e o acesso aos alimentos, mas também ter em análise do relacionado às práticas alimentares a exemplo dos extrativistas e utilização biológica dos alimentos. Para que isso ocorra os diferentes setores da sociedade precisam estar envolvidos e atuantes (LEAO, 2013).

A agricultura familiar e os povos e comunidades tradicionais, com sua capacidade produtiva e de coleta, apoiam no abastecimento do país com produtos alimentícios de forma diversificada e com preservação ambiental. Assim toda intervenção com políticas públicas a este grupo é vista como um mecanismo de autopromoção da segurança alimentar (FAO, 2014).

Uma das estratégias do governo federal em promover a intersetorialidade nas políticas de Segurança Alimentar e Nutricional, para atingir a alimentação saudável e adequada, que integra a Política Nacional de Alimentação e Nutrição (PNAN), por exemplo, foi lançar o Guia Alimentar para a População Brasileira, que entre outros aspectos, valoriza também a promoção de alimentos 
in natura, em especial aqueles produzidos em nível local, visando à biodiversidade e o desenvolvimento sustentável, a chamada "comida de verdade" (BRASIL, 2014; TABAI, 2018).

Segundo Tabai (2017), a segurança alimentar e nutricional ultrapassa sua conceituação como direito humano básico à alimentação adequada, permanente e regular. Pois inclui a soberania alimentar, assegura o alimento do ponto de vista higiênico-sanitário, a diversidade cultural e territorial, e a sustentabilidade ambiental, econômica e social.

A fome e desnutrição são as grandes preocupações do Estado na região Norte e Vale do Jequitinhonha, que historicamente sofre por estar em uma área de baixo Índice de Desenvolvimento Humano (IDH) e percalço da convivência com a seca do semiárido. Sendo uma opção ao fomento de políticas públicas que fortaleçam as agroindústrias de frutos, em especial aqueles regionais e tradicionais do cerrado (BISPO, 2014).

\section{Agroindústria Familiar}

A produção agroindustrial proporciona a oportunidade da população agroextrativista local em organizar-se e gerar melhor condição de vida e qualidade alimentar; garantindo a soberania alimentar e a segurança alimentar e nutricional por meio da coleta de frutos do cerrado. Para tanto, os agroextrativistas precisam ser assistidos por assistência técnica e capacitações de gestão dos empreendimentos, pois apenas direcionar os esforços simplesmente para constituir unidades produtivas não tem surtido efeito sustentável para estas agroindústrias (MELO e VIEIRA, 2012).

Devido às limitações de gerência das agroindústrias familiares, a busca da gestão participativa tem grande importância para formar bons gestores e permitir que os grupos passem por desafios frequentemente, como na divisão dos trabalhos e atividades para que a produção ocorra (BISPO, 2014).

Não distante, estes projetos ser contemplados com investimentos que fomentem a produção e comercialização local de alimentos, reforma agrária, ações de infraestrutura e expansão local do emprego e renda (TABAI, 2017).

A agroindústria da comunidade de Água Doce em Bonito de Minas-MG, tem o papel de oportunizar que os agroextrativistas possam aumentar os estoques de alimentos para além da safra de frutos do cerrado.

\section{A Intersetorialidade}

A intersetorialidade promove a unificação das políticas públicas destinadas à proteção, inclusão e enfrentamento das expressões sociais. Articulando-se para integrar e promover ações em torno de objetivos comuns para a sociedade (CAVALCANTI et al., 2013). 
A intersetorialidade como sendo uma atuação conjunta dos setores governamentais, sociedade civil e parcerias privados têm como estratégia de gestão, a integração que permita uma utilização produtiva das diferenças entre eles, criando melhores soluções para os problemas sociais (CUNILL - GRAU, 2014) e com isso instituir a prática e cultura de gestão.

Segundo Pires (2016) a intersetorialidade requer ação coletiva de forma cotidiana e com envolvimento dos atores que vivenciam o problema que a política pública quer resolver e até então foram construídos e operam de forma fragmentada.

Acredita-se que a intersetorialidade se aplicada as diversas políticas, entre as quais, especialmente as de saúde e alimentação, pode levar os indivíduos a melhoria das suas condições de vida e, consequentemente, propicia maior segurança alimentar e nutricional. Atingir a segurança alimentar por meio de políticas públicas tem sido o objetivo nos últimos anos de alguns programas governamentais, observa-se que cada vez mais as pessoas estão preocupadas com a alimentação de uma forma geral (TABAI, 2017).

Em relação à intersetorialidade, Romagnoli (2017) verifica sua atuação nas limitações estruturais da sociedade brasileira, no que tange o atendimento à população que convive com o problema, sendo apontado a formação de uma rede de proteção social capaz de integrar entre setores e instituições governamentais e não governamentais. Para tanto a gestão pública precisa inovar em arranjos horizontais de trabalho e fazer das experiências e trocas de informações nos espaços propositivos uma constante reflexão das políticas públicas e o seu papel na melhoria da qualidade de vida da população.

Devido a importância do tema e a escassez de trabalhos disponíveis que tratem sobre esses assuntos, na atualidade, para a população brasileira, esse projeto tem por objetivo traçar uma análise da percepção de atores sociais chave na execução e envolvimento com políticas públicas de segurança alimentar e nutricional e no fomento a agroindústria familiar, apresentando a intersetorialidade como processo de efetivação das ações previstas no Plano Plurianual de Ações Governamentais/PPAG 2016 - 2019 do estado de Minas Gerais. O objetivo específico a ser desenvolvido tramita na análise com os atores chave a efetivação destas políticas no ambiente da agroindústria.

\section{MATERIAL E MÉTODOS}

A metodologia de análise qualitativa baseou-se em dados primários e secundários empíricos ocorridos na gestão do governo de Minas Gerais. A Análise das ações de Segurança Alimentar e Nutricional e a Agroindustrialização familiar no governo de Minas Gerais, ocorreram com foco os anos 2016 a 2019. 
Quanto à abordagem da intersetorialidade em ações de SAN e agroindustrialização no estado de MG envolvendo a agroindústria de Água Doce, neste estudo empírico está sendo classificado segundo Vergara (2016), como pesquisa qualitativa, sem análise de dados estatísticos e possuindo como base o conhecimento teórico empírico que permite atribuir-lhe cientificidade. A pesquisa buscou descrever os fenômenos por meio dos significados que o ambiente manifesta os resultados de transcrição de entrevistas e documentos oficiais do Estado de MG, por isso classifica-se quanto ao objetivo da pesquisa como descritivas, sendo que não desconsidera inserção de outras formarem, meios e fins para entender o problema e propor alternativas e soluções (GIL, 2008).

A metodologia compreendeu nas técnicas de pesquisa como: pesquisa bibliográfica, pesquisa de análise documental e entrevistas semiestruturadas com gestores envolvidos com a execução das ações, programas e projetos originários de políticas públicas. Na pesquisa bibliográfica ocorreram levantamentos de estudos nos temas: segurança alimentar e nutricional, agroindústria familiar e intersetorialidade disposta como instrumentos de consulta artigos científicos disponíveis nas bibliotecas eletrônicas como Scielo e sites de busca como o Google acadêmico e livros.

Da pesquisa documental, foram levantados e analisados: leis, decretos e resoluções (MINAS GERAIS, 2016a; 2016c; 2016e; 2018a); catálogos dos Planos Plurianuais de Ação Governamental (MINAS GERAIS, 2016d) e do Planos Mineiro de Desenvolvimento Integrado (MINAS GERAIS, 2016b); relatos descritos como o Relatórios de Monitoramento do PPAG da Secretaria de Estado de Desenvolvimento e Integração do Norte e Nordeste de Minas Gerais (SEDINOR) / Instituto de Desenvolvimento do Norte e Nordeste de Minas Gerais (IDENE) e da Secretaria de Estado de Desenvolvimento Agrário (SEDA) (MINAS GERAIS, 2018) e relatórios de monitoramento do setorial no Sistema de Informações Gerenciais e de Planejamento (SIGPLAN) e Sistema de Controle Social - MG PLANEJA nos quais foi possível obter informações detalhadas sobre valores e entregas nas ações que vinculam a segurança alimentar e nutricional e a agroindústria familiar (SIGPLAN, 2018).

Foram identificados no monitoramento da Assembleia Legislativa de Minas Gerais, 7 programas que tratam de forma direta ou indireta de ações voltadas a segurança alimentar e nutricional, agroindustrialização familiar e a intersetorialidade por meio do Monitoramento das Ações do Planejamento do Estado, acompanhados pela Comissão de Agropecuária e Agroindústria (ALMG, 2018).

No material estudado, foram analisados os desempenhos das secretarias de governo e autarquias descritos no Quadro 1. Estes órgãos públicos, tem suas ações executadas de forma 
independente e setorizada nos descritivos dos documentos. Para verificar a prática de ações intersetoriais foram selecionadas duas secretarias (SEDINOR/IDENE e SEDA) que durante o ano de 2018 se propunham a desenvolver atividades de apoio a agroindústria familiar e política públicas de SAN em seus programas e ações do PPAG 2016 - 2019, exercício 2018.

\section{Quadro 1 - Seleção de Programas e Ações com tema de segurança alimentar e nutricional e agroindustrialização para agricultura familiar na ALMG, Belo Horizonte - MG, 2018.}

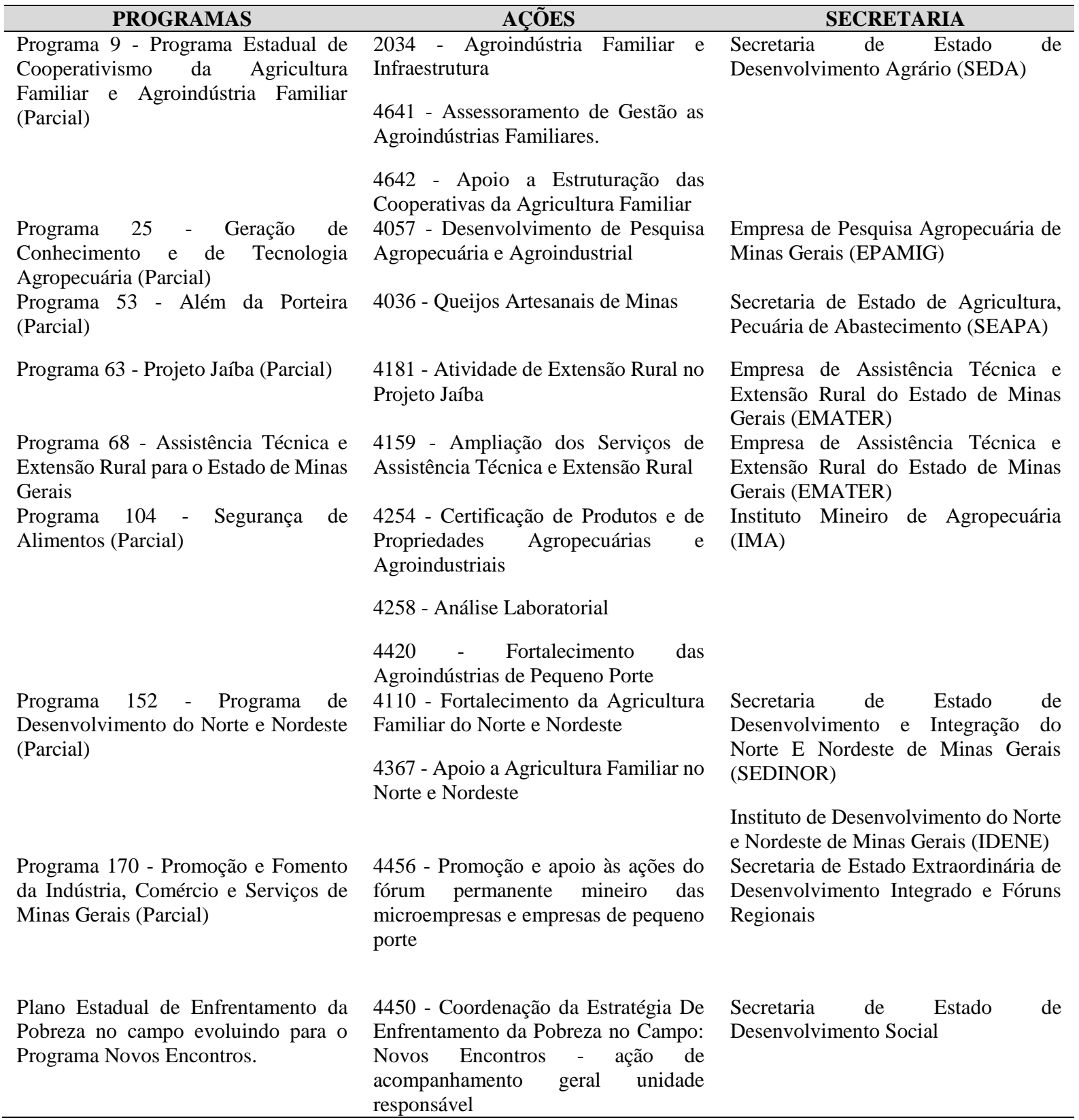

Fonte: Elaboração própria, PPAG 2016 - 2019 (ALMG, 2018; MINAS GERAIS, 2018b). 
Segundo Sampaio (2017), em seu trabalho demonstrando como a intersetorialidade se expressa na gestão da Política Estadual de Segurança Alimentar e Nutricional Sustentável do Estado de Minas Gerais, no período de 2012-2017 foram necessários mecanismos de partilha de informações e comunicação entre os setores.

O Programa Novos Encontros - Estratégia de Enfrentamento da Pobreza no Campo, lançado esteve representado no Plano Mineiro de Desenvolvimento Integrado, por meio do objetivo estratégico de "Reduzir a pobreza rural" e foi uma das prioridades do governo para atingir metas de segurança alimentar e nutricional.

Os dados foram a base de estudos analisados com os entrevistados em complemento com o questionário formulado para confirmação dos programas e ações pertencerem a secretaria que estavam vinculados e se de fato contemplava a temática de SAN e agroindústria familiar onde foram contempladas ações de políticas públicas na região de Bonito de Minas-MG.

Sendo verificados nestes documentos, informações que tivesse relevância para entender e demonstrar como se deram as políticas públicas que beneficiaram a unidade de beneficiamento de plantas e frutos do cerrado de da comunidade de Água Doce em Bonito de Minas e as relações entre os gestores e suas instituições.

Ocorreram ainda, entrevistas presenciais com 7 servidores públicos e 2 representantes da sociedade civil que se caracterizavam como atores-chave no processo de promoção da intersetorialidade por meio de um roteiro semiestruturado, com questões de percepção das políticas públicas de SAN, agroindústria familiar e intersetorialidade, que são os marcos analíticos.

Os entrevistados foram selecionados conforme a atuação em políticas públicas que de alguma forma beneficiaram a agroindústria e a aplicação das entrevistas semiestruturadas aconteceram em dois momentos, sendo o primeiro em novembro/dezembro de 2018 e o segundo em janeiro/fevereiro de 2019, pois no período ocorreram troca de governo estadual e o autor optou por entrevistar servidores de ambas gestões

Os entrevistados selecionados fizeram ou faziam parte da gestão de ações dentro do PPAG que envolve atividades na garantia da SAN e no fomento a agroindustrialização no Estado. A fim de reservar o anonimato dos entrevistados, os mesmos foram identificados no texto por meio da letra E, e uma numeração de 1 a 9 sendo eles da gestão 2015/2018: Na (SEDINOR) representados por E1 e E2, no (IDENE), representados por E3 e na (SEDA) foram entrevistados E4 e E5. Na gestão 2019/2022: dentro do IDENE foram entrevistados E6 e E7. Também foram convidados representantes da sociedade civil, sendo entrevistados um empreendedor privado (E8) e uma gestora de projetos (E9), que estavam envolvidos indiretamente com a execução de políticas públicas e participavam de espaços de intersetorialidade. 
Após as entrevistas realizadas, estas foram transcritas e analisadas em seu conteúdo e procedeu-se sua classificação conforme as dimensões elencadas no marco analítico, posteriormente referenciado como: a percepção do conceito de intersetorialidade, o planejamento de políticas públicas em relação ao processo intersetorialidade, o envolvimento dos atores atuantes na política pública, os desafios da intersetorialidade para promoção da SAN e da Agroindustrialização, o papel da política pública para promoção da SAN e Agroindustrialização de base familiar e o acesso das políticas públicas vivenciadas pela agroindústria de comunidade de Água Doce em Bonito de Minas.

\section{RESULTADOS E DISCUSSÃO}

\section{A Percepção do Conceito de Intersetorialidade}

Nas narrativas, o entendimento dos entrevistados sobre o que é a intersetorialidade indicou como sendo as novas estratégias de atuação da gestão pública, na quebrar da tradicional forma de executar as políticas públicas. O conceito muitas vezes foi citado em termos ambíguos, que no decorrer das narrativas foram sendo firmados assertivamente pelos próprios entrevistados. A intersetorialidade como sendo junção de esforços (E4) para efetivação das políticas públicas e ainda ação coletiva (E8) para garantir a melhoria de vida dos indivíduos que a política pública quer atingir.

Para ocorrer ações intersetoriais há necessidade de decisões políticas, com as articulações e interlocução das gestões e técnicas, assegurando infraestrutura e comprometimento das relações intersetoriais. A intersetorialidade vem apoiada no campo das políticas sociais e pode ser uma alternativa para a promoção da eficiência e produzir resultados eficazes das ações públicas perante o contexto analisado do problema (JACCOUD, 2016).

Intersetorialidade para mim é a junção de esforços para diversos, principalmente, órgão governamentais nas três esferas [...]que busca implementação de políticas públicas [...]pois de maneira geral essa área que trabalhamos segurança alimentar e nutricional, de agricultura familiar, de agroindústria familiar não resolve numa caixinha só do governo...resolve em várias. (E4).

Percebe-se que nas conceituações foram destacadas narrativas que citam a intersetorialidade como sendo uma atuação conjunta dos setores (E2), para chegar a um objetivo comum, na gestão da política pública. Esta atuação conjunta se retrata na forma de reuniões intersetoriais, trocas de informações em grupo temáticos, conselhos e em espaços, com a sociedade civil organizada: 
A intersetorialidade nos conselhos que participo é muito importante, principalmente para o empoderamento da mulher ...quando com as outras secretarias ou outros conselhos [...] o esforço é muito grande [...] não é em todos os momentos e aspectos[...] mas nos desdobramentos[...] ocorre separações comissões, grupos temáticos daí consegue perceber a intersetorialidade para enfim aplicar a política pública. (E2)

A intersetorialidade é conceituada por Cavalcanti et al., (2013) de forma a contemplar muitas narrativas nas entrevistas, pois assume as ações conjuntas e redes de cooperação e produção que se deseja na região, superando superação da fragmentação da atenção às necessidades sociais da população.

A intersetorialidade é uma resposta prática da população insatisfeita com os baixos retornos das políticas públicas que junto de diferentes atores social se articula e promove o trabalho conjunto com os diversos setores, diferentes poderes e conhecimentos múltiplos para resolver problemas complexos.

\section{O Planejamento das Políticas Públicas em Relação à Intersetorialidade}

No Plano Mineiro de Desenvolvimento Integrado (MINAS GERAIS, 2016a; 2016b), o planejamento se constitui a longo prazo, 2016 - 2027, permitindo ao governo nortear as ações. No que tange a ideia de desenvolvimento econômico social sustentável, no PMDI, temos que as políticas públicas "só fazem sentido se houver equilíbrio entre prosperidade social, proteção ambiental e desenvolvimento econômico". Em seu eixo 1: Desenvolvimento Produtivo, Cientifico e Tecnológico, seção: Agricultura, Pecuária e Abastecimento e Desenvolvimento Agrário temos claramente descritos dentre diferentes objetivos estratégicos, os de interesse deste trabalho:

Promover a agroindustrialização ... a produção sustentável e competitiva das cadeias produtivas da agropecuária e fomentar a segurança alimentar e nutricional sustentável, incluindo o acesso e o uso sustentável da água (MINAS GERAIS, 2016a).

Quando analisadas as peças orçamentárias e o planejamento dos programas e ações, são verificadas repetições de ações e atividades para o mesmo público. Cada setor simplesmente executa suas ações, sem com isso interagir com outras secretarias ou até mesmo setores da mesma secretaria. É perceptível em algumas narrativas a compreensão da intersetorialidade como sendo fragmentada e compartimentalizada nos diferentes setores, de estruturas rígidas, das secretarias de governo.

As próprias peças orçamentárias [...] são dificultadoras de intersetorialidade, pois como no PPAG [...] ocorre o controle externo pela ALMG, mas internamente o gestor daquela ação quer fazer o máximo possível que está sob sua responsabilidade. (E4) 
Para alguns entrevistados, a criação de espaços de discussão da intersetorialidade deve partir de forma institucional (E1), pois assim os gestores em suas estruturas hierárquicas terão maior compromisso em integrar as ações.

O Estado tem que criar a ambiência para que a intersetorialidade aconteça, porque qualquer órgão que tente fazer, ele tem um esforço muito grande para convencer as outras pessoas de que isso é importante, de que isso dá resultado[...] o sistema de cobrança do resultado das operações do Estado leva a isso, cada qual tem de mostrar a sua parte ai [sic] não consegue juntar para fazer esta intersetorialidade de grande monta[sic]. (E1)

Nos comentários foram expostas as experiências que cada secretaria ou setor tiveram em relação à intersetorialidade diante de parceiros institucionais e da organização Civil (E1).

[Intersetorialidade] a gente tem exemplos muitos recentes desses últimos quatro anos que são fantásticos [...] os projetos de frutos do cerrado são compostos de intersetorialidade muito grande no Conselho estadual Pró-pequi. O Núcleo do pequi, que é uma organização da sociedade civil [...] tem uma participação ativa $e$ vem conseguido agregado[...] como a CODEVASF, com um trabalho interessante [...] e todos os órgão do governo de Estado...puxados pelo IDENE. (E1)

A intersetorialidade deve ser praticada e também ensinada. Houve entrevistado (E4) que citou a necessidade de espaços de formação e capacitação de gestores no tema de forma constante.

Para que isso de fato aconteça (intersetorialidade) o gestor tem que estar preparado, então é preciso pensar um processo permanente de formação, de capacitação de gestores, sejam eles efetivos, sejam eles de recrutamento amplo para poder entender como interagir e não simplesmente como se executa ali na sua caixinha [...] se executa aquela política pública de forma a integrar outros setores outros órgãos dentro do Estado. (E4).

\section{O Envolvimento dos Atores Atuantes nas Políticas Públicas}

$\mathrm{Na}$ pesquisa procurou-se saber o compartilhamento de responsabilidades e ações das secretarias e como os entrevistados percebiam este comportamento na prática. A apropriação dos resultados dos diferentes atores é um fator de relevância, pois em diferentes narrativas os entrevistados (E2) descreveram o quanto as ações são conduzidas por pessoas que tem o interesse de ajudar e que o envolvimento se diferencia quanto à afinidade dos temas das ações com o setor e com o servidor. As atribuições dentro do processo de intersetorialidade devem ser compartilhadas entre todos os agentes governamentais, pois quando ocorre concentração de atividades a pequenos grupos ou individuais o processo torna-se frágil e não permite avançar (CUSTÓDIO; SILVA, 2015). 
[...] intersetorialidade vai ser uma das formas que se tem que entender como as políticas públicas têm que acontecer, para que cheguem de fato ao seu público alvo que é a sociedade civil organizada ou não [...] a intersetorialidade vai nos permitir compreender como que a junção do entendimento do fazer do Estado, o fazer do governo tem formas concretas de virar o que são as políticas públicas ou seja atendimento das necessidades que a sociedade possa nos trazer ou possa nos demandar. (E2)

Quando ocorrem os espaços de integração das ações, a intersetorialidade, a participação da sociedade civil e movimentos sociais é posta e respeitada, sendo estes espaços uma forma de contemplar as demandas da sociedade e que de fato ocorra a política pública.

\section{Os Desafios da Intersetorialidade para Promoção da SAN e Agroindustrialização}

O monitoramento e avaliação dos programas e ações do governo de MG são feitos pelos sistemas MG - Planeja, onde as informações são disponíveis ao público comum, apresentando parte do planejamento, acompanhamento e governança das ações prioritárias do governo e no SIGPLAN, que é de uso das secretarias onde constam as informações sobre o desenvolvimento dos programas e ações que compõe o PPAG, dando suporte para os setores monitorar e avaliar as próprias ações (MINAS GERAIS, 2016b). Por mais que a sociedade civil tenha acesso ao PPAG as ações propostas nem sempre estão vinculadas a prática da intersetorialidade e os sistemas de monitoramento contribui para que isso permaneça desconexo, pois são estruturas que avaliam e monitoram dados específicos e setorizados.

As dificuldades de se colocar em prática a intersetorialidade têm diferentes motivos e origens. Percebe-se que a falta de comunicação é um fator para que não ocorra a discussão dos temas de forma integrada (E4). Não diferente, há falta de espaços de diálogo do problema vivenciado sobre o tema e até mesmo de unificação de ações para dentro do próprio órgão executor da ação.

[...] tem pouco diálogo na mesma esfera estadual [...] na própria secretaria ou dentro do próprio órgão, há setores que cuidam e não dialogam [...] como deveriam entre si[...] intersetorialidade para mim é justamente esta articulação esse esforço, essa coesão que tem que ter para que a política pública seja de fato implementada. (E4)

Procurou-se observar a predisposição de conflitos na promoção da intersetorialidade, nas narrativas dos entrevistados, ou especificamente exemplificados e como eram solucionados.

Quando da questão de ciúme institucional um dos entrevistados (E1) evidenciou que ocorre e é um fator de dificuldade, pois os programas e ações sendo compatibilizados por secretarias de governo têm se a ideia de posse. 
[...] tem sido tentado (intersetorialidade) porque tem uma dificuldade muito grande por conta da questão do ciúme institucional[...]mas conseguimos avançar [...] mas foi um pedaço pequeno diante do que poderia ter feito...tem que ter um direcionamento de governo para que isso aconteça[...] não é a vontade de uma instituição que aparece e sim a visão do técnico. (E1)

Para parte dos entrevistados, diferente de se ter conflitos, um dos grandes problemas é falta de clareza em saber o que está fazendo e o resultado daquele esforço. Em muitos casos a falta de entendimento das ações e o não entendimento de onde queremos chegar, desmotiva aqueles que estão na execução da política pública.

\section{O Papel da Política Pública para Promoção da SAN e Agroindustrialização de Base Familiar}

No Programa Novos Encontros - Estratégia de Enfrentamento da Pobreza no Campo foi verificado um maior engajamento para ocorrer a prática da intersetorialidade em ações de segurança alimentar e nutricional. A interação ocorreu por formação de grupos de trabalho com discussões temáticas (SAMPAIO, 2017). É percebido maior foco de ações e controle por parte da secretaria de governo do Estado.

O Programa Novos Encontros, mesmo não constando no PPAG, foi uma das prioridades do Governo de Minas dentro da estratégia de "Reduzir a pobreza rural” (MINAS GERAIS, 2016b) que promoveu atividades intersetoriais e materializou-se na composição de um Grupo Coordenador da Estratégia (MINAS GERAIS, 2016e), cujos membros foram representantes de 11 órgãos e 8 empresas e instituições de ensino e pesquisa do Estado.

O programa foi dividido em 4 eixos: Acesso a Serviços, Benefícios e Transferência de Renda; Inclusão Produtiva; Infraestrutura e; Acesso à Terra; sendo que no eixo "Inclusão produtiva" tem como sub eixos: Assistência Técnica e Extensão Rural, Segurança Alimentar e Nutricional, e Trabalho e Renda. Um dos projetos deste eixo, Projeto Sementes Presentes, permitiu a inclusão da população em situação de vulnerabilidade social no processo produtivo, com a doação de sementes para garantir a segurança alimentar e colaborar com a geração de renda com excedente.

A exemplo da SEDINOR/IDENE, foram verificados aporte de projetos de acesso a água, distribuição de leite pasteurizado e sementes para plantios. $\mathrm{Na}$ ação denominada Apoio à Agricultura Familiar, a agroindústria de processamento de leite e frutas teve aporte de recursos e processos de articulação junto de outras secretarias e organizações da sociedade civil (SIGPLA, 2018).

O entrevistado E3 ilustra essa integração em ações que ocorreram em sua instituição na prática de intersetorialidade em benefício da segurança alimentar e nutricional. 
[...] A ideia de desenvolvimento é você associar as ações que se tenha dentro do órgão com outros órgãos para se unificar e ter uma ação mais efetiva [...] nós (IDENE) executamos as cisternas (Caixa de água da chuva para alimentação) $e$ depois as cisternas de produção (Caixa de água da chuva para produção). Essas cisternas de produção foram construídas em diversas comunidades rurais, agrovilas, comunidades carentes e comunidades com baixa captação de recursos hídricos [...] mas aquelas comunidades ainda não tinham condição de ter uma produção[...] então nós fizemos a entrega de tratores para preparar a terra, integrar as comunidades [...] e entregamos sementes para agricultura familiar. Essa integração foi o que tentamos fazer...temos um banco de dados que cruza as ações e os próprios beneficiários, assim fechamos os ciclos. (E3)

A SEDA junto do Conselho Diretor Pró - Pequi, organizou em 2016 um chamando público (Fomento) para apoiar as cadeias produtivas de frutos do cerrado.

Na oportunidade a associação Núcleo Gestor da Cadeia Produtiva de Pequi e Outros Frutos do Cerrado captou um recurso de $\mathrm{R} \$ 49.900,00$, onde constava em seu plano de trabalho consultoria e cursos ligados a processamento de frutos e boas práticas de higiene em 9 unidades de processamento de frutos do cerrado, entre elas a unidade de Bonito de Minas. O representante da agroindústria participou e multiplicou o conhecimento com agroextrativistas.

Segundo o entrevistado E5, quando do período dos editais, muitas solicitações e préprojetos não foram financiados, pois, a contingenciamento de gastos já ocorria no estado e muitas das ações no período foram não orçamentárias. O corpo técnico da secretaria tinha em sua rotina de trabalho elaborar projetos que no futuro pudessem ser aprovados ou ter outras formas de financiamento.

[...] Os editais que fizemos para agroindústrias em 2015 e 2016 foram 115 projetos de associações das mais variadas, um percentual bom foi de agroindústria [...] As ações específicas, uma coisa que fizemos muito foram projetos [...] projeto de adequação das instalações, para associação, para prefeitura, para comunidades como ações não orçamentarias [...] pois a maioria deles não tem orientação técnica e é um custo muito caro contratar um engenheiro civil, um arquiteto [...] então disponibilizamos o corpo de servidores técnico da secretaria [...]. Se não podíamos financiar, elaborávamos os projetos com os técnicos que já estavam aqui, adequando as atividades da rotina deles [...] Como não podíamos ajudar a todos, aqueles que a equipe técnica conseguia ajudar, eram menos uma possibilidade de custos ao beneficiário... contamos com a boa vontade dos técnicos e por mais que alguns não fossem os responsáveis técnicos, os projetos ficaram estruturados e prontos. Foram 30 a 35 projetos de adequação de agroindústria [...] as ações orçamentárias foram poucas diante daquelas não orçamentarias. (E5)

Segundo Santos e Freitas (2017) a arbitragem de cortes ou contenção do orçamento anual nas políticas públicas devem ter uma análise dos impactos e seus efeitos diretos, indiretos, econômicos e sociais do setor agropecuário / agroindustrial. E que da mesma forma deve-se preservar ações com potencial de dinamização da produção. 
Os agroextrativistas ainda dependem muito de políticas públicas para que sejam contemplados em ações de segurança alimentar e nutricional. Da mesma forma as agroindústrias sem apoio governamental passam por processo que ficam mais demorados e com custos maiores para se tornar efetivos.

\section{O Acesso das Políticas Públicas Vivenciadas Pela Agroindústria de Bonito de Minas.}

Prosseguindo a análise, temos o objeto de estudo da dissertação, a agroindústria de Bonito de Minas, dentro de arranjos institucionais que promoveram políticas públicas intersetoriais e que foram acessadas pelos agroextrativistas.

Após a inauguração da unidade produtiva de frutos do cerrado da comunidade de Água Doce (Bonito de Minas-MG), em 2016, os agroextrativistas foram acompanhados pela associação Núcleo Gestor da Cadeia Produtiva de Pequi e Outros Frutos do Cerrado, apoiados pelo IDENE e a empresa PROBIOMA, esta última financiada pela CODEVASF no projeto: Profissionalização do Extrativismo e Beneficiamento de Plantas e Frutos do Cerrado, apoiado pelo gabinete do Deputado Federal Padre João. A liderança da agroindústria passou a frequentar reuniões de mobilização em rede de cooperação e produção onde participaram diferentes cooperativas, associações, grupos independentes e órgão públicos, com o objetivo de desenvolver a produção de forma sustentável, melhorar a organização das demandas da cadeia produtiva e os grupos agroextrativistas de frutos do cerrado na região.

No tocante a questão, os agroextrativistas da comunidade de Água Doce foram beneficiados na promoção de dois elos importantes para a segurança alimentar e nutricional, quais sejam a disponibilidade de alimentos em quantidade suficiente e a preços acessíveis e o acesso ao trabalho e renda, oferecidas na agroindústria que se enquadra como de menor porte, pequeno varejo e serviços de alimentação (MALUF e PRADO, 2015).

A governança da rede de cooperação e produção é feita pelo Conselho Diretor Pró - Pequi, que era vinculado à SEDA, atualmente subordinada à Secretaria de Estado de Agricultura, Pecuária e Abastecimento, e os agroextrativistas que participavam da elaboração e execução das políticas públicas para a cadeia produtiva. O Projeto da associação Núcleo do Pequi: Organizações na busca de aprimoramento técnico para fortalecer o Agroextrativismo Sustentável e a Economia Solidária no Norte de Minas, financiado pela SEDA em 2016 atendeu a 9 instituições (cooperativas e associações).

As diretrizes de intersetorialidade descritas no plano de governo ocorreram na rede de forma dinâmica e participativa, com apoio dos próprios agroextrativistas e diferentes setores públicos e organizações da sociedade civil. 
Para o empreendedor, o conceito de intersetorialidade, mesmo que complementando aos dos servidores públicos, foi diferenciado e reflete mais a situação da agroindústria que prestava serviço a humanidade com produtos de transcende a alimentação, pois busca qualidade de vida e boa saúde.

$\mathrm{Na}$ entrevista com o empresário identificado como E8, a intersetorialidade também é importante para a manutenção do negócio uma vez que as empresas têm acesso ao mercado e a produção da agroindústria, com isso consegue-se parcerias para a rede de cooperação e produção, fechando o ciclo.

Enquanto empresa da área de produtos e serviços ambientais, nós temos uma facilidade de buscar essas parcerias, desenvolver clientes, plataformas para colocar produção nesse mercado que não é um mercado trivial é um mercado que valoriza produtos agroecológicos, que são nutracêuticos [...], não são apenas nutritivos eles têm papel farmacêutico. (E8)

Segundo Vogt (2019) a agricultura exercida no mundo está fracassada nos quesitos ambiental e social, sendo urgente a necessidade de mudança nos sistemas alimentares. Em sua proposta os sistemas baseados na agroecologia são os que oferecem efeitos mais duradouros para a humanidade e ao planeta.

Quando verificados os desafios da aplicação de política pública de fomento a agroindustrialização familiar, o papel do Estado e do capital privado devem ser mais claros e diferenciados, conforme E8.

É função do Estado prover meio para que as comunidades se desenvolvam e para isso é necessária ter estruturas, acessos, políticas claras, orientação técnicatecnológica para que as pessoas saiam do estado inicial. A partir daí nós (agroextrativista) [sic] temos várias possibilidades de envolver novos produtos e serviço em parcerias com empresas. E essas empresas vão abrir mercado para essas instituições, para essas pessoas que estão no campo. (E8)

Cabendo ao setor público, em sua gestão, proporcionar a transparência e facilidade de acesso aos dados das políticas públicas aos agroextrativistas e agricultores familiares, pois assim desenvolve-se políticas intersetoriais promovendo a geração de renda, acesso a mercados e melhorias na atuação das políticas de segurança alimentar e nutricional (MONTEIRO, 2019).

A intersetorialidade com envolvimento da sociedade civil tem que ter dentro do processo os agroextrativistas segundo o entrevistado E9, de forma presente e atuantes, diante das políticas públicas. Para que isso ocorra, há necessidade de melhor clareza e diálogos mais direcionados aos beneficiados da ponta e com isso oportunizar e ampliar o acesso a direitos sociais, e ainda, enfatizar o investimento nos processos de empoderamento dos atores envolvidos (RODRIGUES, 2011). 
Na minha opinião (não está chegando as políticas públicas) penso que a questão de linguagem agente ainda precisa... traduzir para o agroextrativista. Nós temos no nosso púbico, um público com baixa escolaridade. (E9)

Em relação à promoção da segurança alimentar e nutricional, o apoio do Estado diante de políticas intersetoriais tem facilitado que as agroindústrias se organizem para fornecer produtos as escolas por meio de programas como Programa Nacional de Alimentação Escolar - PNAE.

Na mesorregião de Januária uma das políticas que mais tem sido acessada é o PNAE [...] essa sim tem garantido uma soberania alimentar no sentido de melhorar a qualidade dos produtos e chegar também esse acesso nas escolas para que as pessoas possam ter uma qualidade de vida melhor. (E9)

A percepção nas entrevistas do grupo de 2019 apontou que a avaliação da intersetorialidade das políticas de agroindustrialização tem grande comprometimento no governo. Isso está ilustrado na fala do entrevistado denominado E6.

$\mathrm{Na}$ verdade, os dois devem caminhar juntos, a agroindústria familiar ou agroindústria [...] vejo nas diversas esferas governamentais, sociais $e$ empresariais que todo mundo quer fazer o bem, que todo mundo quer o desenvolvimento. E a participação desses atores, está começando, de maneira ainda incipiente a trabalhar junto, já foi tentado outras vezes e a gente não pode desistir disso [...] se a gente olhar o passado em comparação com agora eu vejo que melhorou bastante, mas ainda tem muito o que se fazer. (E6)

Os entrevistados descrevem, em sua maioria, o quanto é difícil para o Estado o planejamento da intersetorialidade na prática, principalmente por causa da estrutura setorializada. O Estado trabalha com uma estrutura de orçamento - programa em que as ações dentro de cada secretaria compõem os objetivos dos programas de governo que são intersetoriais. Essas diferentes ações deveriam contribuir para alcançar o objetivo geral do programa e assim seria possível perceber o funcionamento da intersetorialidade. Quando no PPAG, de forma teórica, isto é descrito e funciona bem, mas falta mecanismo formal para acompanhar todas as ações e execuções orçamentárias e por mais que a Secretaria de Estado de Planejamento e Gestão de Minas Gerais (SEPLAG) tente, há muito a ser compartilhado.

Para um dos entrevistados uma solução deste problema seria a criação de grupos de trabalho, não formalizados (E7), mas que tenha afinidades e consigam entender o trabalho de cada secretaria e tenham diretrizes claras para traçar estratégias para que os grupos perpetuem e entendam os resultados a médio e longo prazo, não optando por imediatismo.

Um grupo de trabalho... uma mesa formada... sem entrar no mérito de conselhos... pois quando cai nessa estrutura formais mais complexas agente traz muito problemas junto, mas talvez um grupo de trabalho que se reunisse periodicamente, que conversasse com órgão afins que entendesse o que cada um está fazendo e como poderia se complementar. (E7) 
A contenção de gastos atuou em todas as ações previstas no PPAG estudado, não apenas na temática de segurança alimentar e nutricional e agroindustrialização familiar. Em muitos casos os replanejamentos com redução de custos frente à situação orçamentária do Estado (SAMPAIO, 2017), o que não oportunizou mais efetivações de ações.

Assim, por mais que ocorram atividades de mobilização e articulação no planejamento e na execução das atividades propostas junto dos gestores, a falta de recursos financeiros impede que os trabalhos tenham continuidade.

\section{CONSIDERAÇÕES FINAIS}

Por meio de atores sociais na rede de cooperação e produção dos agroextrativistas do norte de Minas Gerais, foi confirmada a importância e o entendimento das práticas de intersetorialidade neste ambiente onde a agroindústria de Bonito de Minas foi inserida. Em principal, pela aprovação de projetos das secretarias (SEDA e SEDINOR, atualmente SEAPA e SEDE) que atenderam a demandas da agroindústria e da comunidade de Água Doce de forma geral.

O governo de Minas Gerais tem abordado a intersetorialidade de forma pragmática em programas e projetos, sendo percebidos no Plano Plurianual de Ação Governamental em determinadas secretarias.

Há necessidade de melhorar os planejamentos intersetoriais para ações que não tenha ações e atividades executáveis apenas na constância de recursos financeiros. As articulações e mobilizações de grupos de cooperação e produção saem dos momentos de retração econômica estadual e nacional.

O apoio na agroindústria em 2018 - 2019 ocorreu dentro da rede de cooperação e produção com apoio da CODEVASF. As atividades do projeto permitiram a continuidade do apoio a cadeia produtiva e aos que dela se beneficiam.

O desafio para a prática da intersetorialidade está na visão do gestor em toda sua cadeia hierárquica. O planejamento, assim como o monitoramento dos programas e ações que visem o apoio a agricultura familiar e suas agroindústrias precisam ser revisado, assim como outras políticas públicas no Estado. O planejamento deve preceder o momento do PPAG e seu monitoramento, um planejamento mais eficiente dentro das estruturas hierárquicas mais altas e próximas do governador para que o Estado em suas propostas consiga ser eficiente e eficaz nas políticas públicas. 
No material pesquisado foram percebidas que muitas ações, em anos diferentes não foram executadas ou ficaram a aquém do planejado. Muito se justificou pela retração econômica nacional que aflige, ainda hoje, o Estado de forma significativa, penalizando o desenvolvimento regional.

\section{REFERÊNCIAS}

ASSEMBLEIA LEGISLATIVA DO ESTADO DE MINAS GERAIS - ALMG. 2018. Monitoramento das Ações do Planejamento do Estado, 2018. Disponível em: $<$ https://politicaspublicas.almg.gov.br/temas/monitoramento.html?tagNivel1=6001\&tagAtual=10 067>. Acesso em: 20 de nov. 2018.

BISPO, Tayline Walverde. Agroextrativismo no Vale do Rio Urucuia - Minas Gerais: formas de organização da produção e da distribuição. 2014, 146f. Dissertação de Mestrado. Universidade de Brasília. Faculdade de Agronomia e Medicina Veterinária. Brasilia - DF, 2014.

BRASIL. Ministério da Saúde. Secretaria de Atenção à Saúde. Departamento de Atenção Básica. Guia alimentar para a população brasileira/Ministério da Saúde, Secretaria de Atenção à Saúde, Departamento de Atenção Básica. 2. ed. Brasília: Ministério da Saúde. 2014. 156 p.

BURITY, Valéria.; FRANCESCHINI, Thaís; VALENTE, Flávio.; RECINE, Elizabetta; LEÃO, Marília; CARVALHO, Maria de Fatima. Direito Humano à Alimentação Adequada no Contexto da Segurança Alimentar e Nutricional. Ação Brasileira pela Nutrição e Direitos Humanos (ABRANDH). 2010. 204 p.

CAVALCANTI, Patrícia Barreto; BATISTA; Káttia Gerlânia Soares; SILVA, Leandro Roque. A estratégia da intersetorialidade como mecanismo de articulação nas ações de saúde e assistência social no município de Cajazeiras - PB. In: Anais do Seminário Internacional sobre Políticas Públicas, Intersetorialidade e Famílias, v. 1, 2013. p. 32. Disponível em: <http://ebooks.pucrs.br/edipucrs/anais/sipinf/edicoes/I/9.pdf>. Acesso em: 20 de nov. 2018.

CUNILL - GRAU, Nuria. La intersectorialidad em las nuevas políticas sociales: um acercamiento analítico - conceptual. Gestyón y Política Pública, v. 23 n. 1, p. 5 - 46, 2014. Disponível em: <http://www.gestionypoliticapublica.cide.edu/numanteriores/Vol.XXIII_NoI/01\%20GyPP\%20N uria\%20Cunill\%20(1 - 46).pdf>. Acesso em: 02 nov. 2018.

CUSTÓDIO, André Viana; SILVA, Cícero Ricardo Cavalcante. A intersetorialidade nas políticas sociais públicas. In: Seminário Nacional Demandas Sociais e Políticas Públicas na Sociedade Contemporânea, I Mostra Nacional de Trabalho Científicos. Anais... Santa Cruz do Sul, RS: UNISC, $\quad$ p. $\quad 3 \quad-\quad$ 18, $2015 . \quad$ Disponível em: <https://online.unisc.br/acadnet/anais/index.php/snpp/article/viewFile/14264/270>. Acesso em:12 out. 2019.

FOOD AND AGRICULTURE ORGANIZATION OF THE UNITED NATIONS - FAO. O Estado da Segurança Alimentar e Nutricional no Brasil: Um Retrato Multidimensional Relatório 2014. Brasília, 2014. 90 p. Disponível em: <https://www.fao.org.br/download/SO FI_p.pdf>. Acesso em: 4 dez. 2018. 
GIL, Antônio Carlos. Métodos e Técnicas de Pesquisa Social. 6 ed. São Paulo: Atlas. 2008. 200 p.

GAZOLLA, Márcio. Segurança alimentar e nutricional e agroindústrias familiares: políticas públicas e ações locais. Segurança Alimentar e Nutricional, v. 21, n. 2, p. 527 - 540, 2014. Disponível

em:

<https://periodicos.sbu.unicamp.br/ojs/index.php/san/article/view/8634629/2550>. Acesso em: 28 nov. 2018.

JACCOUD, Luciana. Pobreza, direitos e intersetorialidade na evolução recente da proteção social brasileira. In: MACEDO, Juliana Matoso.; XEREZ, Flávia Helena Saraiva.; LOFRANO, Rodrigo (Org). Intersetorialidade nas políticas sociais: perspectivas a partir do programa Bolsa Família. Brasília, DF: Ministério do Desenvolvimento Social e Combate à Fome; Secretaria de Avaliação e Gestão da Informação, 2016, p. 15 - 34. (Cadernos de Estudos Desenvolvimento Social em Debate, 26) Brasília, 2016.20 Disponível <https://aplicacoes.mds.gov.br/sagirmps/ferramentas/docs/Caderno\%20de\%20Estudos\%2026.pd f>. Acessado em: 28 ago. 2019.

LEÃO, Marília. O direito humano à alimentação adequada e o sistema nacional de segurança alimentar e nutricional / organizadora - Brasília: ABRANDH. 2013. 263 p. Disponível em: $\langle$ http://www.mds.gov.br/webarquivos/publicacao/seguranca_alimentar/DHAA_SAN.pdf $>$.

Acessado em: 28 ago. 2019.

MALUF, Renato Sérgio Jamil; PRADO, Bruno Azevedo. Atuação na América Latina e Caribe relacionada com a soberania e segurança alimentar e nutricional. Rio de Janeiro: Centro de Referência em Segurança Alimentar e Nutricional (CERESAN). Textos para Discussão 8. 2015. 62 p. Disponível em: content/uploads/2016/docs/Cooperacao_em_SAN_na_ALeC.pdf>. Acesso em: 10 nov. 2019.

MELO, Aurélio Alves; VIEIRA, Fernanda Rodrigues. Agricultura familiar competitiva: um diagnóstico estratégico da agroindústria de processamento de frutas e vegetais pertencente a cooperativa de agricultura familiar de Itapuranga - Goiás. Enciclopédia Biosfera, v. 8, n.15, p. $55-68,2012$.

MINAS GERAIS. Lei Estadual n ${ }^{\circ} 21.967$, de 12 de janeiro de 2016: Atualiza o Plano Mineiro de Desenvolvimento Integrado e dá outras providências - PMDI 2016-2027. Belo Horizonte, 2016a. Disponível em: https://www.mg.gov.br/sites/default/files/transicaogovernamental/Cat\%C3\%A1logo\%20PMDI\%20Volume\%201.pdf . Acesso em: 02 agostos de 2019.

MINAS GERAIS. Subsecretaria de Planejamento, Orçamento e Qualidade do Gasto. Superintendência Central de Planejamento e Programação Orçamentária: Catálogo Plano Mineiro de Desenvolvimento Integrado- PMDI 2016-2027. Belo Horizonte. 2016b. 98 p. Disponível em: $\quad$ https://www.mg.gov.br/sites/default/files/transicaogovernamental/Cat\%C3\%A1logo\%20PMDI\%20Volume\%201.pdf>. Acesso em: 16 abr. 2019.

MINAS GERAIS. Lei Estadual no 21.968, de 14 janeiro 2016: Institui o Plano Plurianual de Ação Governamental para o quadriênio 2016-2019. Belo Horizonte, 2016c. Disponível em: $<$ https://www.almg.gov.br/consulte/legislacao/completa/completa-nova-

Min.html?tipo=LEI\&num $=21968 \&$ comp $=\& a n o=2016 \&$ texto $=$ consolidado\#texto $>$. Acesso em: 16 abr. 2019. 
Subsecretaria de Planejamento, Orçamento e Qualidade do Gasto. Superintendência Central de Planejamento e Programação Orçamentária: Catálogo Plano Plurianual de Ação Governamental - PPAG 2016 -2019. Belo Horizonte, v. 1, 2016d. 2074 p. Disponível em:< https://www.almg.gov.br/acompanhe/planejamento orcamento_publico/ppag/20162019/2016/documentos/ppag_2016-2019_volume1.pdf>. Acesso em: 16 abr. 2019.

Decreto com numeração especial 339, de 29 de junho de 2016. Cria Grupo Coordenador das ações de enfrentamento da pobreza no campo, no âmbito da Administração Pública Estadual. Minas Gerais, Belo Horizonte, 2016e. Disponível em: <http://www.almg.gov.br/consulte/legislacao/completa/completa.html?num=339\&ano=2016\&t ipo=DNE $>$. Acesso em: 01 agosto de 2019.

\section{Lei Estadual n ${ }^{\circ} 22.942$, de 2018, dispõe sobre a revisão do Plano Plurianual}

de Ação Governamental (PPAG) 2016-2019 para o exercício 2018. 2018a. Disponível em: <https://www.almg.gov.br/consulte/legislacao/completa/completa-novamin.html?tipo=LEI\&num $=22942 \& \mathrm{comp}=\& a n o=2018 \&$ texto=original\#texto $>$. Acesso em: 16 abr. 2019.

Subsecretaria de Planejamento, Orçamento e Qualidade do Gasto. Superintendência Central de Planejamento e Programação Orçamentária. Relatório Institucional de Monitoramento PPAG 2016 - 2019: Revisão 2018. Belo Horizonte: 2018b. Disponível em: $<$ https://www.almg.gov.br/export/sites/default/acompanhe/planejamento_orcamento_publico/ppa g/2016 - 2019/2018/monitoramento/abas/governo/documentos/relatorio - do - governo - janeiro junho - 2018.pdf>. Acesso em: 02 ago. 2019.

MONTEIRO, Barbara Leandro. Políticas Públicas de Fortalecimento da Agricultura Familiar e Segurança Alimentar e Nutricional (SAN): Programa de Aquisição de Alimentos e o Programa Nacional de Alimentação Escolar no Município de Crato - CE. 2019. 120f. Dissertação (Mestrado) - Universidade Federal Rural do Rio de Janeiro. Programa de Pós-Graduação em Agricultura Organica, Seropedica - RJ, 2019.

NEVES, Daniele Custódio Gonçalves. Análise de Políticas Públicas Intersetoriais de Fortalecimento da Agricultura Familiar e de Segurança Alimentar e Nutricional no Brasil e o caso de um município do Espírito Santo. 2017, 104f. Dissertação (Mestrado em Práticas de Desenvolvimento Sustentável). Instituto de Florestas. Universidade Federal Rural do Rio de Janeiro, Seropédica, RJ, 2017.

PIRES, Roberto Rocha Coelho. Intersetorialidade, arranjos institucionais e instrumentos da ação pública. Brasília: Ministério do Desenvolvimento Social e Combate à Fome. Cadernos de Estudos Desenvolvimento Social em Debate, n. 26. 2016. Disponível em: http://aplicacoes.mds.gov.br/sagirmps/ferramentas/docs/Caderno\%20de\%20Estudos\%2026.pdf>. Acesso em: 20 nov. 2018.

RODRIGUES, Jovina Moreira Sérvulo. A intersetorialidade entre as políticas públicas de saúde e de assistência social pós constituição brasileira de 1988. V Jornada Internacional de Políticas Públicas. Anais eletrônicos... São Luís: UFMA, 2011. Disponível em: http://www.joinpp.ufma.br/jornadas/joinpp2011/CdVjornada/JORNADA_EIXO_2011/IMPASS ES E DESAFIOS_DAS_POLITICAS_DA_SEGURIDADE_SOCIAL/A_INTERSETORIALID ADE_ENTRE_AS_POLITICAS_PUBLICAS_DE_SAUDE.pdf>. Acesso em: 20 set. 2029. 
ROMAGNOLI, Roberta Carvalho. Transversalizando as Políticas Públicas: Quando a Intersetorialidade se Torna Rizomática. Pontifícia Universidade Católica de Minas Gerais (PUC MG), Belo Horizonte - MG, Brasil: Psicol. Estud, v. 22, n. 3, p. 421 - 432. 2017.

SAMPAIO, Estefânia Viana. A intersetorialidade nas ações de promoção da segurança alimentar e nutricional do Estado de Minas Gerais (2012 - 2017). 2017. 169 f. Monografia (Graduação em Administração Pública, Escola de Governo Professor Paulo Neves de Carvalho - Fundação João Pinheiro, Belo Horizonte - MG, 2017.

SANTOS, Gesmar Rosa dos; FREITAS, Rogério Edivaldo. Gasto Público com a Agricultura no Brasil: Uma Abordagem a partir de Dados Agregados. Boletim regional, urbano e ambiental.

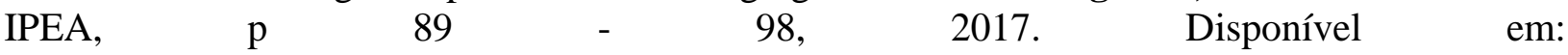
<http://repositorio.ipea.gov.br/bitstream/11058/8159/1/BRU_n17_Gasto.pdf> Acesso em: 20 mar. 2020.

SIGPLAN, 2018-Sistema de Informações Gerenciais e de Planejamento do Plano Plurianual. Disponível em: 〈https://www.sigplan.mg.gov.br/v4/appHome> Acesso em: 01 ago. 2019.

TABAI, Katia Cilene. A Segurança Alimentar e Nutricional no contexto da intersetorialidade. In: AZEREDO, Denise Rosane Perdomo. (Org.). Inocuidade dos Alimentos. São Paulo: Ed. Atheneu, p. 19 - 30, 2017.

Políticas de segurança alimentar e saúde pública. In: SARTORIO, Lúcia Aparecida Valadares. Org. Sustentabilidade: qualidade de vida, economia solidaria e educação. Nova Iguaçu: Ed. Entorno, p. 137 - 156, 2018.

VERGARA, Sylvia Constant. Projetos e Relatórios de Pesquisa em Administração. 16. ed. São Paulo: Atlas. 2016.104 p.

VOGT, Flávio. Alimentos Orgânicos na Percepção de Diferentes Atores Sociais do Município de Frederico Westphalen - RS. 2019. 56f. Dissertação (Mestrado) - Universidade Federal Rural do Rio de Janeiro. Programa de Pós-Graduação em Agricultura Organica, Seropédica - RJ, 2019. 